How do schools compensate for socio-economic disadvantage?

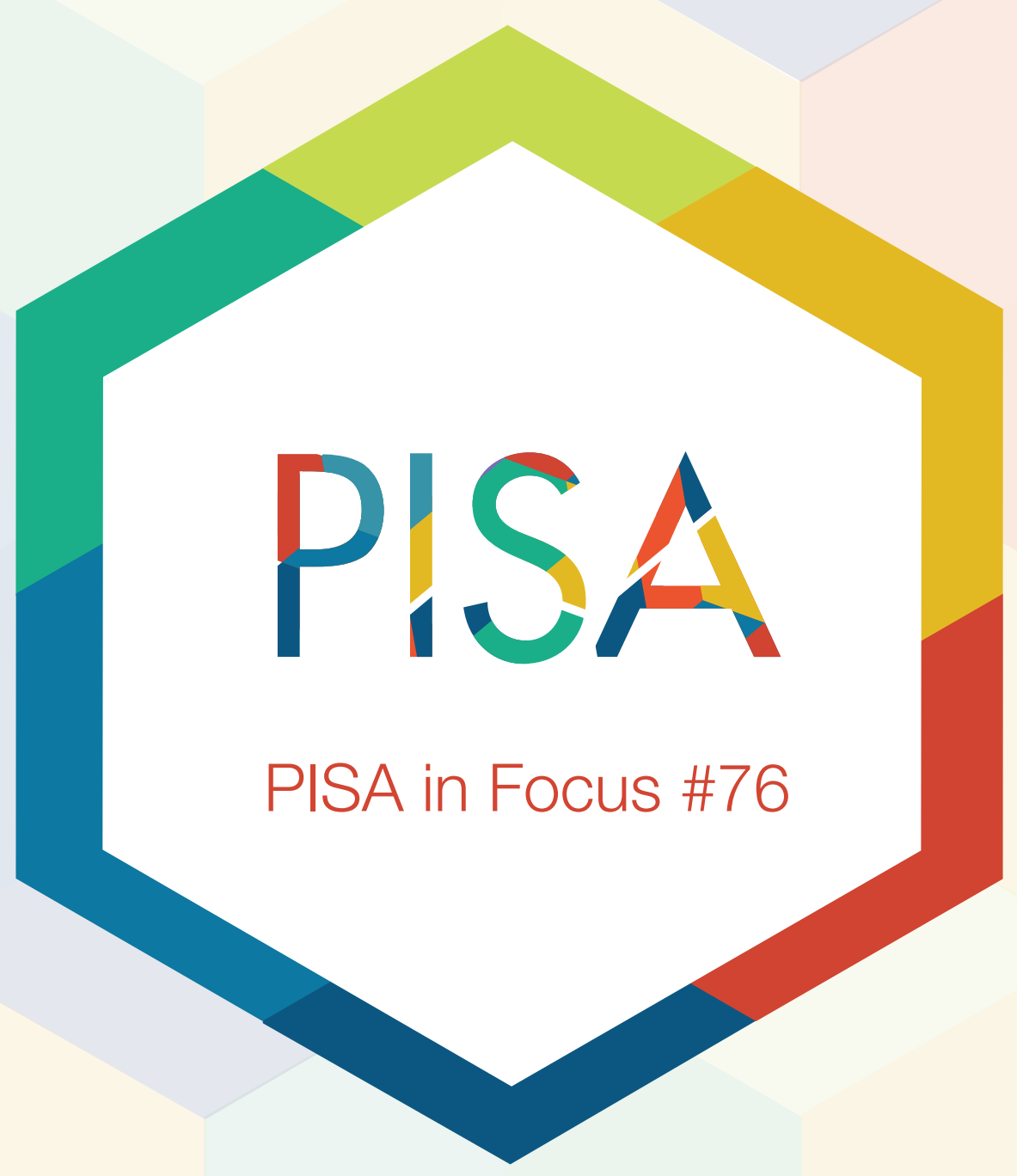




\section{How do schools compensate for socio-economic disadvantage?}

- Students perform better in science when they attend schools with effective learning environments (including adaptive and teacher-directed instruction, good disciplinary climate and required attendance at science lessons) and high-quality educational resources (including science teachers, laboratories and extracurricular activities), on average, after accounting for the socio-economic profile of students and schools.

- Supportive environments and quality resources are more frequently found in socio-economically advantaged schools, suggesting that schools often amplify, rather than compensate for, students' home resources. But in Estonia, Israel, Latvia, Macao (China), Montenegro, Norway and Tunisia, students in disadvantaged schools have access to learning environments and resources of comparable quality (or better, in some respects) as their peers in advantaged schools.

- About one-third of the variation in science performance across OECD countries is explained by the degree of equity in the allocation of educational resources across advantaged and disadvantaged schools, with more equitable systems performing better, on average.

As educators know well, there are many barriers to learning that originate outside of school, such as those that arise from socio-economic disadvantage. In many education systems, the concentration of disadvantaged students in certain schools poses an additional challenge. Yet it is also true that schools with effective learning environments and high-quality resources can compensate, at least partially, for larger social inequalities. If school systems are to level the playing field, so that all children, regardless of their family background, are offered the best possible education, then the types of practices and resources that are related to better student performance need to be used in every school, not just in advantaged schools.

\section{What schools do, and the resources they have, matter for student performance.}

PISA 2015 results show that, across all participating countries and economies, 26\% of the variation in science performance is observed between schools, 22\% between school systems, and the remaining 53\% between students. This means that, even if students' individual characteristics - such as their gender or their socioeconomic status - tend to have a strong impact on their science performance, what happens in the school and in the classroom makes a crucial difference.

For example, the way teachers teach science is strongly associated with science performance. Students score higher in science when they reported that their science teachers "adapt the lesson to their needs and knowledge" or "provide individual help when a student has difficulties understanding a topic or task" (adaptive instruction). Students also score higher in science when they reported that their science teachers "explain scientific ideas", "discuss their questions" or "demonstrate an idea" (teacher-directed instruction) more frequently.

Students tend to perform better in schools that provide an environment that is conducive to learning. Most of all, this means that students listen to the teacher, treat other students with respect, and do not disrupt the flow of instruction (disciplinary climate). It also means that, according to students, their teachers show an interest in every student, provide extra help when needed and give students opportunities to express their ideas (teacher support). When students perceive that their teachers are supportive and treat them fairly, they tend to have a stronger sense of belonging at school that, in turn, has a positive impact on both their academic performance and satistaction with life. 
School factors positively associated with science performance Multilevel regression models of education systems, schools and students

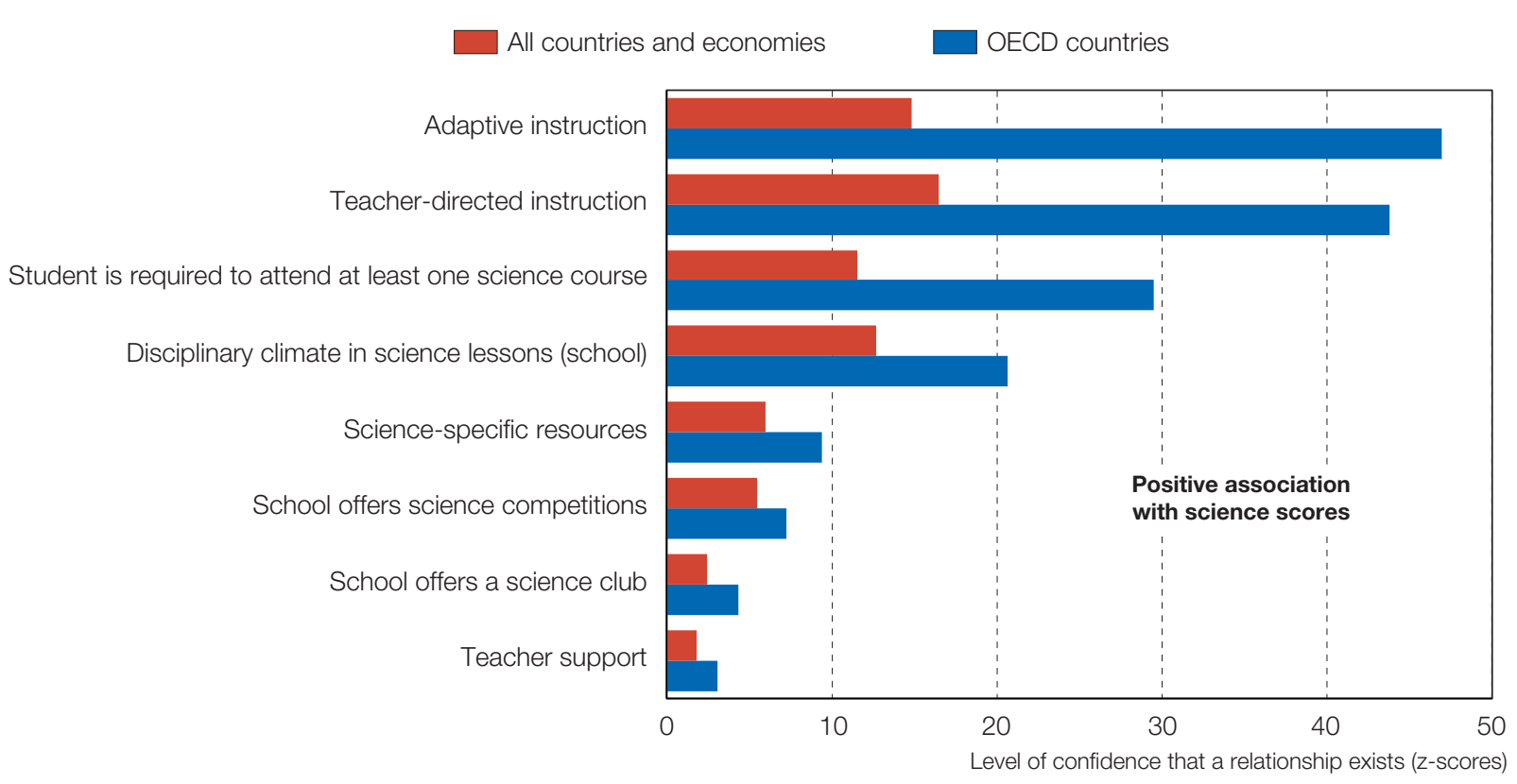

Notes: All variables have been introduced jointly in a three-level regression model. The figure includes only school-level variables whith a positive association with science scores.

Statistically significant coefficients have associated z-scores above 1.96

The model accounts for students' and schools' socio-economic status and other variables.

See Figure II.7.2 in OECD (2016), PISA 2015 Results Nolume II), for a complete list of the variables in the model.

Factors are ranked in descending order of the z-scores for OECD countries.

Source: OECD (2016), PISA 2015 Results Nolume II): Policies and Practices for Successful Schools, Figure II.7.2.

Exposure to science instruction is also important. Students in schools that require them to attend at least one science course per week score higher than students who are not required to attend any science lesson. Their poor performance might be one of the reasons why these students do not take science courses in the first place; but cutting them off from school science entirely might only widen the performance gap between them and their better-performing peers.

Ensuring access to various educational resources, and the capacity of school staff to make the best use of those resources, is another way for schools to help students. PISA finds that students perform better in science when schools have qualified science teachers, and high-quality laboratory and other materials for hands-on activities in science classes, and in schools that offer science-related extracurricular activities, such as science clubs or competitions.

\section{Effective practices and quality resources are more often found in advantaged schools.}

PISA 2015 results also find that the learning environments in socio-economically advantaged and disadvantaged schools can be drastically different.

For example, in 37 of 69 countries and economies, teachers in advantaged schools use teacher-directed instruction more frequently than teachers in disadvantaged schools do. In 16 countries and economies, adaptive instruction is also more frequently used in advantaged schools than in disadvantaged schools, although in Belgium, Croatia, France, Israel, Italy, Latvia, Montenegro and Spain, adaptive instruction is used more frequently in disadvantaged schools. 
Differences between advantaged and disadvantaged schools in school factors that affect performance

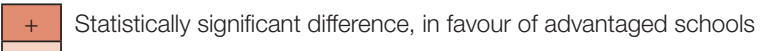

Statistically significant difference, in favour of disadvantaged schools

Difference is not statistically significant

m Missing data

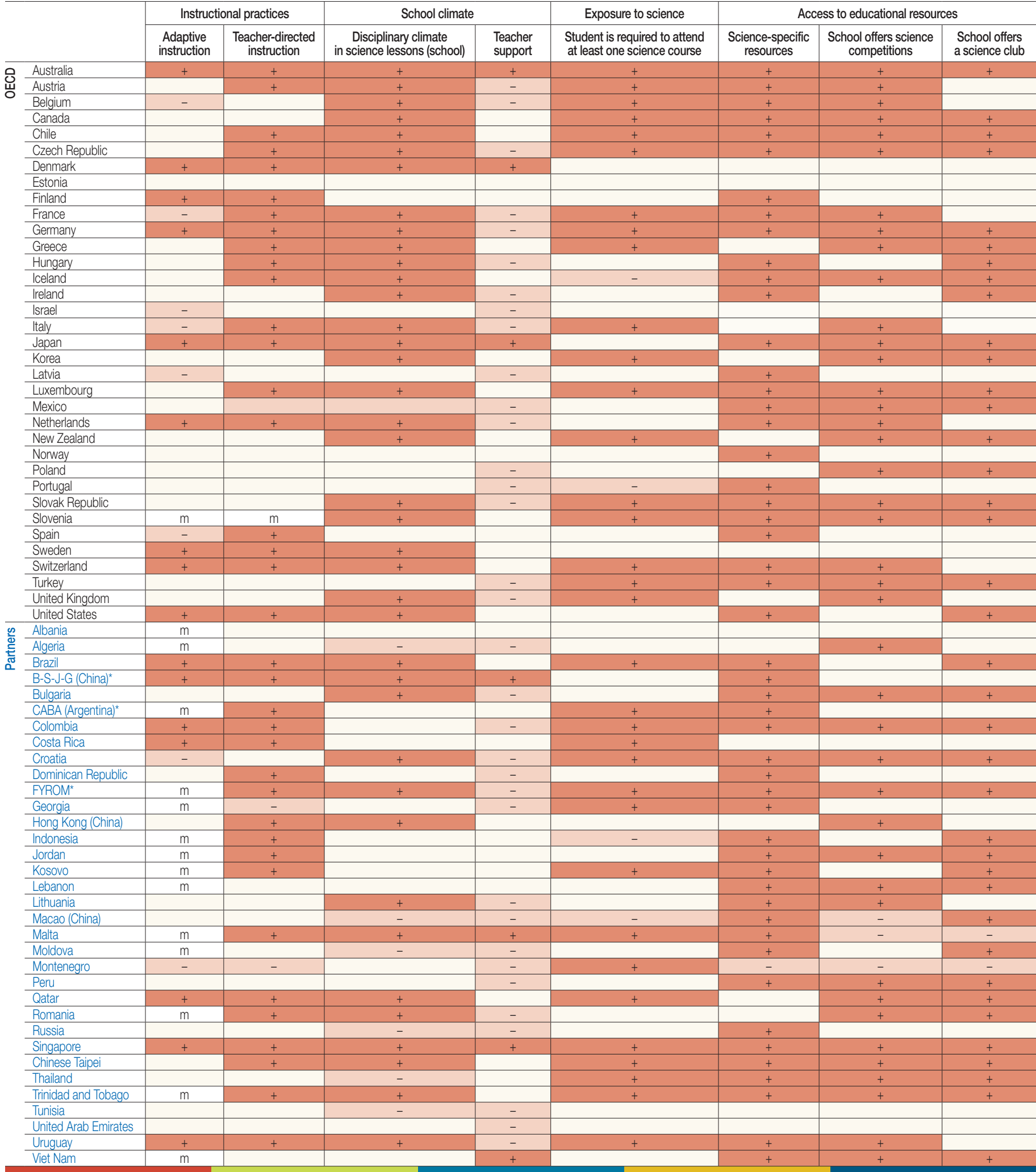

* B-S-J-G (China) refers to the four PISA participating China provinces: Beijing, Shanghai, Jiangsu, Guangdong. CABA (Argentina) refers to Ciudad Autónoma de Buenos Aires, Argentina. FYROM refers to the Former Yugoslav Republic of Macedonia.

Note: A socio-economically disadvantaged (advantaged) school is a school in the bottom (top) quarter of the school-level PISA index of economic, social and cultural status within each country/economy.

Source: OECD, PISA 2015 Database. 
PISA also finds that, in 39 countries and economies, the disciplinary climate in science lessons is better in advantaged schools than in disadvantaged schools. The relationship between disciplinary climate and socio-economic advantage is the strongest among all factors examined here. But in Algeria, Macao (China), Moldova, the Russian Federation, Thailand and Tunisia, it is among disadvantaged schools that classroom discipline is better, signalling that schools can, in some contexts, manage the greater risk of disruptive behaviour at school that is common among disadvantaged students. Further, there are school systems (such as those of Estonia, Finland and Norway) where school discipline does not differ between disadvantaged and advantaged schools; these systems manage to combine high levels of performance in PISA with equity.

In 34 countries and economies, students in disadvantaged schools were more likely than those in advantaged schools to report that their teachers are supportive; in only 7 countries/economies is the reverse observed. Although the strength of the relationship between teacher support and performance is somewhat weaker than other factors, this is a notable exception to the pattern of better practices observed in advantaged schools. It is possible that, because disadvantaged schools tend to have larger shares of students who are poor, immigrant, non-native speaking or from single-parent families - all of which can have an impact on learning teachers in these schools tend to be more supportive of students. The result might also signal a way through which some disadvantaged schools help their students overcome structural barriers to learning.

In 34 countries and economies, students in advantaged schools are more frequently required than students in disadvantaged schools to take at least one science course. The exceptions are Iceland, Indonesia, Macao (China) and Portugal, where students in disadvantaged schools are more frequently required to take science courses.

When it comes to the quality of educational resources, advantaged schools clearly have the edge. In 50 countries and economies, educational resources specific to science classes are more widely available in advantaged schools; Montenegro is the only country in PISA 2015 where disadvantaged schools have higher-quality sciencespecific resources than advantaged schools. In addition, the range of learning opportunities beyond regular classes is also much narrower in disadvantaged schools, as these schools tend to offer fewer extracurricular activities, such as science competitions and clubs, and fewer sports, music and arts activities.

\section{Successful school systems provide additional support to disadvantaged schools.}

Allocating additional resources to socio-economically disadvantaged schools is not only a way to compensate inequalities across schools; it can also help improve overall student performance in science. Indeed, about one-third of the variation in science performance across OECD countries is explained by the degree of equity in the allocation of educational resources across advantaged and disadvantaged schools, with more equitable systems performing better, on average. The performance of the weakest students appears to benefit the most, and not at the expense of the highest-performing students, when relatively more resources are allocated more equitably.

\section{The bottom line}

Students in socio-economically disadvantaged schools are less exposed than students in advantaged schools to the learning environments and educational resources that matter the most for science performance. If schools are to compensate for inequalities in family background, effective teaching practices, good disciplinary climates, greater exposure to high-quality science instruction, and qualified science teachers and materials should be available in all schools. Allocating resources more equitably across schools is a key first step to achieving this goal. School systems that already combine high performance and equity show that offering high-quality education opportunities to all students is possible. 


\section{For more information}

Contact: Daniel Salinas (Daniel.Salinas@oecd.org)

See: OECD (2017), PISA 2015 Results (Volume III): Students' Well-Being, OECD Publishing, Paris, http://dx.doi.org/10.1787/9789264273856-en.

OECD (2016), PISA 2015 Results (Volume II): Policies and Practices for Successful Schools, OECD Publishing, Paris, http://dx.doi.org/10.1787/9789264267510-en.

OECD (2016a), Low-Performing Students: Why They Fall Behind and How To Help Them Succeed, OECD Publishing, Paris, http://dx.doi.org/10.1787/9789264250246-en.

Coming next month: How does PISA assess collaborative problem solving?

This paper is published under the responsibility of the Secretary-General of the OECD. The opinions expressed and the arguments employed herein do not necessarily reflect the official views of OECD member countries.

This document, as well as any data and map included herein, are without prejudice to the status of or sovereignty over any territory, to the delimitation of international frontiers and boundaries and to the name of any territory, city or area.

The statistical data for Israel are supplied by and under the responsibility of the relevant Israeli authorities. The use of such data by the OECD is without prejudice to the status of the Golan Heights, East Jerusalem and Israeli settlements in the West Bank under the terms of international law.

This work is available under the Creative Commons Attribution-NonCommercial-ShareAlike 3.0 IGO (CC BY-NC-SA 3.0 IGO). For specific information regarding the scope and terms of the licence as well as possible commercial use of this work or the use of PISA data please consult Terms and Conditions on www.oecd.org. 